\title{
ULTRASTRUCTURAL AND MUSCULAR MODIFICATIONS OF ADULT SCHISTOSOMA MANSONI WORMS INDUCED BY ARTEMETHER (ART) IN VITRO
}

By

\author{
MAHMOUD A. ELSHAFEY ${ }^{1}$, SAMIA E. ETEWA ${ }^{2}$, MOHAMED H. SARHAN ${ }^{2 *}$, \\ SALWA Z. A. ARAFA ${ }^{3}$, DALIA A. ABO EL-MAATY ${ }^{2}$ \\ AND ABD-ALLAH A. A. ALHOOT ${ }^{3}$ \\ Departments of Clinical Pathology ${ }^{1}$, Medical Parasitology ${ }^{2}$, Faculty of Medicine and \\ Department of Zoology ${ }^{3}$, Faculty of Science, Zagazig University, Egypt \\ ( ${ }^{\star}$ Correspondence: drsarhan@gmail.com) \\ Abstract
}

Schistosomiasis is one of the most important public health problems worldwide. In spite of two decades of safe and effective widespread chemotherapy with praziquantel, the number of individuals with schistosomiasis remains high with the appearance of drug resistance. So, it diverts the attention to other anti-parasitic drugs like artemesinin derivatives e.g. artemether (ART).

This study was done to assess the effects of ART on the tegument and musculature of adult Schistosoma mansoni worms in vitro.

Five groups of $S$. mansoni coupled adult worms, each of 10 couples, were used. Four groups were tested in vitro using different concentrations of ART $(20,40,80$ and $100 \mu \mathrm{g} / \mathrm{ml})$ for 24 hours of exposure. These adult worms were obtained by hepatic perfusion technique seven weeks postinfection by $100 \pm 10 \mathrm{~S}$. mansoni cercariae in male white albino mice using tail immersion method. Ultrastructural and muscular modifications of adult S. mansoni worms were assessed using Scanning Electron Microscopy (SEM) and a special device respectively.

SEM examination revealed that after 24 hours of exposure to $40 \mu \mathrm{g} / \mathrm{ml}$ ART, the tegument showed vesicles and loss of spines. On exposure to $80 \mu \mathrm{g} / \mathrm{ml}$ ART, the tegument showed cracking and more loss of spines. After exposure to $100 \mu \mathrm{g} / \mathrm{ml}$ ART, tegument appeared mostly distorted with cracking, peeling, bleb formation and the spines covering the tubercles appeared to be partially lost.

ART elicited muscle contraction and reached the highest response with $100 \mu \mathrm{g} / \mathrm{ml}$ ART. The maximal increase in muscle tension (\% shortening of worms) was $44.1 \pm 1.79 \%$ shortening induced by the highest concentration $(100 \mu \mathrm{g} / \mathrm{ml})$ of ART.

Keywords: Schistosoma manosni, coupled adult worms, artemether, in vitro, scanning electron microscope, tegument, muscle tension.

\section{Introduction}

Schistosomiasis was reported from 78 countries, of which 52 endemic countries with moderate-to-high transmission. About 218 million persons living in rural and agricultural areas are estimated of requiring preventive treatment (WHO, 2017). In spite of decades of widespread chemotherapy, the number of individuals with schistosomiasis remains high (King, 2007). So, it diverts the attention to other parasitic drugs like artemesinin.

Artemesinin and its derivatives are effective anti-malarial drugs (McIntosh and Olliaro, 2000). The active principle is obtained from the stems of the leaves of Artemisia annua, a plant used in Chinese traditional medicine (Klayman, 1985). In 1982, Chinese parasitologists discovered that administration of ART (methyl ether derivative of dihydroartemesinin) to mice infected with $S$. japonicum resulted in significant reductions of Schistosoma worm burden (Le et al, 1982). ART showed in vivo activity against adult schistosomes characterized by hepatic shift, degeneration of reproductive organs and hence inhibiting egg formation, and decrease of worm body size, which eventually led to death (Hamza et al, 2012).

The ultra-structural study of adult worms clarified the effects of some drugs on the adult worms such as the tegumental changes like swelling, fusion of tegumental ridges, formation of vesicles, peeling and even the 
collapse of the tegument (Xiao et al, 2010; Silva et al, 2014). These ultra-structural observations on the tegumental surface of Schistosoma mansoni were observed by using antischistosomal drugs such as astiban (Otubanjo, 1981), niridazole (Popiel and Erasmus, 1984), oxamniquine (Fallon et al, 1996), praziquantel (Mohamed et al, 2006), thioxo-imidazolidine derivatives (Neves et al, 2011, Silva et al, 2014) and artemether (ART) (Xiao et al, 2002; Hamza et al, 2012). Moreover, Bennet et al (1997) developed a special device to monitor the in vitro effect of praziquantel on adult Schistosoma worm muscle contraction.

From the previous studies on antischistosomal compounds observed so far and due to the great need for more studies on the effective drugs such as ART, the present work was done to investigate the effect of ART on adult $S$. mansoni worms in vitro by ultrastructural and muscular tension study.

\section{Materials and Methods}

The study was conducted from October 2016 to March 2017 in the laboratory of Medical Parasitology Department, Faculty of Medicine, Zagazig University and Electron Microscope Laboratory of Faculty of Science, Zagazig University.

Animals: Male Swiss albino mice (6-8 weeks age $20-25 \mathrm{gm}$ weight) were obtained from the animal house, Theodor Bilharz Research Institute (TBRI), Imbaba, Egypt. Mice were fed with stock commercial pellet diet and were given water ad libitum.

The experimental animal study was carried out according to the international valid guidelines of experimental animal studies. All efforts were made to minimize the animal's suffering.

Parasite: Schistosima mansoni cercariae (Egyptian strain) were collected from infected Biomphlaria alexandrina snails obtained from Schistosoma Biological Supply Program (SBSP), Theodor Bilharz Research Institute (TBRI), after exposure to artificial light for at least 45 minutes.
Drug: ART tablets (50mg, Kunming Pharmaceutical Corporation, Kunming, China) were used in this study. $5 \mathrm{mg}$ of ART was dissolved in $3 \mathrm{ml}$ of polyethylene glycol (PEG) 400 and then diluted to $5 \mathrm{ml}$ with Hanks balanced salt solution (HBSS; M.A. Bioproducts, Walkersville, Md.). Drug solution (50 to $200 \mu \mathrm{l}$ ) was added to 1.8 to 1.95 $\mathrm{ml}$ of medium in each assay dish to yield a final volume of $2 \mathrm{ml}$ for in vitro study. The used concentrations in this study were obtained by calculation of the added ART different weights in $\mu \mathrm{g}$ to the used reagents. ART was applied in concentrations of 20 , $40,80 \& 100 \mu \mathrm{g} / \mathrm{ml}$ over 24 hours of in vitro exposure of $S$. mansoni coupled adult worms to test its effect on the worms' tegument and muscles.

Study design: 30 male white Albino mice were infected with $100 \pm 10$ cercariae for each mouse by tail immersion method (Liang et al, 1987). Seven weeks postinfection, the mice were perfused and adult worms (couples) were collected in RPMI1640 medium and divided into five groups, each in 35 by $10 \mathrm{~mm}$ plastic petri dishes (Falcon, Becton Dickinson Labware, Lincoln Park, NJ). The worms were kept in an incubator at $37^{\circ} \mathrm{C}$ in an atmosphere of $95 \%$ air-5\% $\mathrm{CO}_{2}$. At 1 to 2 hours after incubation, ART solution (60\% PEG 400, 40\% HBSS) was added to the medium, resulting in final drug concentrations of $20,40,80 \& 100 \mu \mathrm{g} /$ $\mathrm{ml}$. The $1^{\text {st }}$ group served as the control group of adult $S$. mansoni worms. The other four groups were investigated by four ascending concentrations of ART $(20,40,80 \& 100$ $\mu \mathrm{g} / \mathrm{ml})$ for 24 hours as follows: $2^{\text {nd }}$ Group: adults tested by $20 \mu \mathrm{g} / \mathrm{ml}$ ART, $3^{\text {rd }}$ Group: adults tested by $40 \mu \mathrm{g} / \mathrm{ml}$ ART, $4^{\text {th }}$ Group: adults tested by $80 \mu \mathrm{g} / \mathrm{ml}$ ART and $5^{\text {th }}$ Group: adults tested by $100 \mu \mathrm{g} / \mathrm{ml}$ ART.

Ultrastructural study: The worms from the tested groups of mice were collected and examined by scanning electron microscopy (SEM). The tested worms were fixed in $25 \%$ gluteraldehyde-phosphate buffer $(0.2 \mathrm{ml}, \mathrm{pH}$ $=7.4$ ) and kept at $4^{\circ} \mathrm{C}$ overnight. Specimens 
were dehydrated in graded ethanol before embedding. Worms were mounted on stainless steel holders and put in a drier for about 24 hours and subjected to sputter coat of gold. Ultrastructure features of Schistosoma worms were the examined using Jeol JEM1200 EXII scanning electron microscope.

Muscular tension study: Muscle tension of worm (\% shortening of worm) was assayed in response to ART in rising concentrations of $20,40,80 \& 100 \mu \mathrm{g} / \mathrm{ml}$ in vitro. The effect was determined by a special device, originally developed by Bennet et al, (1997), consists of a photo-optic transducer with an amplifier capable to measure the worm's muscle contraction (Fig. 1).

Changes in baseline tension after adding ART were measured as: a - Change in worm length $=$ Change in baseline tension $\times$ device calibration $(400 \mu \mathrm{m}), \mathrm{b}-$ Percentage of change in worm length $(\%$ shortening $)=(\mathrm{Ch}-$ ange in worm length/length of worm between two electrodes) $\times 100$. So, if the change in the baseline tension was $8 \mathrm{~mm}$, the change in the worm length $=16 \%$ shortening.

\section{Results}

The surface topography of $S$. mansoni was studied by SEM. Study on the control group revealed no apparent damage. There were numerous large tubercles with apically directed spines (Fig. 2). After exposure of $S$. mansoni to ART in ascending concentra-

Table 1: In vitro effect of increasing doses of ART on muscle tension (\% shortening of worms) of S. mansoni adult

\begin{tabular}{|c|c|}
\hline Dose Conc. & \% shortening of worms \\
\hline $20 \mu \mathrm{g} / \mathrm{ml}$ & $9.7 \pm 1.16 \%$ \\
\hline $40 \mu \mathrm{g} / \mathrm{ml}$ & $19.3 \pm 1.89 \%$ \\
\hline $80 \mu \mathrm{g} / \mathrm{ml}$ & $33.6 \pm 1.78 \%$ \\
\hline $100 \mu \mathrm{g} / \mathrm{ml}$ & $44.1 \pm 1.79 \%$ \\
\hline P-value & $<0.001$ (Significant) \\
\hline
\end{tabular}

\section{Discussion}

Schistosomiasis is considered one of the most important human helminthiasis in terms of morbidity and mortality. Chemotherapy (like praziquantel) is the most widely advocated method of schistosomiasis control (WHO, 1993). ART, the anti-malarial to ART (Xiao et al, 1995; 2000a, b). The highest susceptibility was directed to the tions, all worms showed focal damage of the tegument dorsal surface (Figs. 3-6).

SEM revealed that after 24 hours exposure to ART in concentration of $20 \mu \mathrm{g} / \mathrm{ml}$, the tegument appears oedematous with loss of spines of few tubercles (Fig. 3). After exposure to ART in concentration of $40 \mu \mathrm{g} / \mathrm{ml}$, the tegument showed swelling of the tubercles with vesicle formation and shortening or even loss of the tubercular spines. Finally, tegument appeared with more disruption and more shrinkage of tubercles (Fig. 4). While after exposure to ART in concentration of $80 \mu \mathrm{g} / \mathrm{ml}$, tegument appeared disrupted with cracking and loss of apical tubercular spines (Fig. 5). After exposure to ART in concentration of $100 \mu \mathrm{g} / \mathrm{ml}$, the tegument showed marked cracks and superficial peeling. Tubercles showed distortion and loss of spines with some blebs and absence of intertubercular ridges (Fig. 6).

In the present study, schistosome muscle tension (\% shortening of worms) was assayed in response to ascending concentrations of ART. The drug led to muscle contration and reached the highest response in muscle tension was $44.1 \pm 1.79 \%$ shortening induced by highest concentration $(100 \mu \mathrm{g}$ $/ \mathrm{ml})$ of ART. In vitro effect of increasing doses of ART on muscle tension (\% shortening) of $S$. mansoni adults (Tab. 1, Fig. 7, 8). with $100 \mu \mathrm{g} / \mathrm{ml}$ ART. The maximal increase

drug, may become an alternative therapy to praziquantel as it elicited anti-schistosomal effects (Xiao et al, 2002; Hamza et al, 2012).

There was obvious evidence from laboratory investigations that $S$. japonicum, S. mansoni and $S$. haematobium are susceptible larval migratory stages i.e. immature stages. However, ART also showed in vivo activity 
against adult schistosomes in the form of hepatic shift, degeneration of reproductive organs leading to inhibition of egg formation and reduction of worm body size, which eventually led to death (You et al, 1992; Xiao et al, 1995). So, ART in this study was used in different ascending concentrations in a trial to assess its in vitro anti-schistosomal effects. The maximum dose of ART used in this work is $100 \mu \mathrm{g} / \mathrm{ml}$ as in vitro toxic effects of ART on $S$. mansoni were not seen at concentrations less than $100 \mu \mathrm{g} / \mathrm{ml}$ (Xiao and Catto, 1989).

The tegument of schistosomes and other trematodes has secretory function and is involved in nutrient absorption, protects schistosomes from immune attack by the host and is an important target for antischistosomal drugs (Pearce and Sher, 1987). In common, all drugs were found to induce variable degrees of destruction to the tegument, subtegumental structures and the reproductive system of the adult schistosomes. ART displayed a considerably slower action than praziquantel (Xiao et al, 2000b). So, tegumental changes are very important to assess the effect of ART on adult schistosomes.

Ultrastructural study for examination of the tegument was done using SEM. The 20 $\mu \mathrm{g} / \mathrm{ml}$ concentration of ART produced some changes in the worm surface. These changes included slight disruption of the tegument and loss of spines of few tubercles. After 24 hours of exposure to $40 \mu \mathrm{g} / \mathrm{ml} \mathrm{ART}$, the tegument showed formation of vesicles and more loss of apical tubercular spines. After exposure to $80 \mu \mathrm{g} / \mathrm{ml}$ ART, the tegument showed more damage, more disruption and loss of some tubercular spines. After exposure to $100 \mu \mathrm{g} / \mathrm{ml}$ ART, peeling, cracking and blebs appeared on the tegument with absence of intertubercular rigdes and more loss of spines. These findings were consistent with Xiao et al. (2002), Jiraungkoorshul et al. (2005) and Hamza et al. (2012). The present results were compared to Bricker et al. (1983) work on the in vitro effects of praziquantel monitored by the SEM and showed good achievement.

ART induced cracking of the tegument with variable degrees of distortion of the tegumental matrix. The spines covering the tubercles on the tegument appeared to be lost. Tubercles on the tegument showed damage. These findings agreed with Xiao et al, 2002.

Moreover, Xiao et al. (2002) found that that ART showed marked affection to the gut epithelial cells and vitelline cells, which might further affect the physiological functions of adult worms as functions of the intestine and the production of the eggs by $S$. mansoni females by using different techniques in assessment of different criteria.

In vitro studies have shown that the very early noticeable effect of any drug on the adult worms was the spastic paralysis of the musculature of schistosomes. They showed that the process began as a transient stimulation of muscle tone which eventually leads to shortening of the worm through tetanic contraction (Pax et al, 1978). So, muscle contraction was recorded in this work using a special device to assess muscular tension effects of ART on adult schistosomes.

In the present work, schistosome muscle tension (\% shortening of worm) was assayed in response to different concentrations of ART. It elicited somatic muscle contration and reached the highest response (44.1 \pm $1.79 \%$ shortening) with $100 \mu \mathrm{g} / \mathrm{ml}$ ART. This result was highlighted by Ismail et al. (1999) concerning the in vitro effect of antischistosmal drug (praziquantel) in susceptible and unsusceptible $S$. mansoni.

\section{Conclusion}

The results showed that the in vitro use of ART with different concentrations induced important effects on $S$. mansoni adults with disruption of the worm tegument as monitored by SEM and muscle contraction with worm shortening as recorded by a special device. Thus, ART could be served as a promising anti-schistosomal drug with the need of more work on ART to highlight its other therapeutic effects, mechanism(s) of 
action and toxic effects on immature and mature $S$. mansoni worms.

\section{References}

Bennett, JL, Day, T, Liang, FT, Ismail, M, Farghaly, A, 1997: The development of resistance to anthelmintics: A perspective with an emphasis on the antischistosomal drug praziquantel. Exp. Parasitol. 87, 3:260-7.

Bricker, CS, Depenbusch, JW, Bennett, JL, Thompson, DP, 1983: The relationship between tegumental disruption and muscle contraction in Schistosoma mansoni exposed to various compounds. Z. Parasitenkd. 69, 1:61-71.

Fallon, PG, Fookes, RE, Wharton, GA, 1996: Temporal differences in praziquantel and oxamniquine-induced tegumental damage to adult Schistosoma mansoni: Implications for drugantibody synergy. Parasitology 112:47-58.

Hamza, RS, Metwally, AS, Abo El-Maaty, DA, 2012: Effects of artemesinin treatment on prepatent and patent Schistosoma mansoni infection in experimentally infected mice. PUJ, 5, 2:147-54.

Ismail, M, Botros, S, Metwally, A, William, S, Farghally, A, et al, 1999: Resistance to praziquantel: direct evidence from Schistosoma mansoni isolated from Egyptian villagers. Am. J. Trop. Med. Hyg, 60, 6:932-5.

Jiraungkoorskul, W, Sahaphong, S, Sobhon, $\mathbf{P}$, Riengrojpitak, S, Kangwanrangsan, N, 2005: Effects of praziquantel and artesunate on the tegument of adult Schistosoma mekongi harboured in mice. Parasitol. Int. 54, 3:177-83.

King, CH, 2007: Lifting the burden of schistosomiasis-defining elements of infection-associated disease and the benefits of antiparasite treatment. J. Infect. Dis. 196: 653-5.

Klayman, DL, 1985: Qinghaosu (artemisinin): an antimalarial drug from China. Science 228: 1049-55.

Le, W, You, J, Yang, Y, Mei, J, Guo, H, et al, 1982: Studies on the efficacy of artemether in experimental schistosomiasis. Acta Pharmaceut. Sin. 17:187-93.

Liang. YS, Bruce, JI, Boy, DA, 1987: Laboratory cultivation of schistosome vector snails and maintenance of schistosome life cycles. In: Proceed. $1^{\text {st }}$ Sino-American Symposium 1:34-48.

McIntosh, HM, Olliaro, P, 2000: Artemisinin derivatives for treating severe malaria. Cochrane Database Syst. Rev. 2:CD000527.

Mohamed, AH, Ezz El-Din, N, Fahmy, ZH,
El-Shennawy, AM, Hassan, E, 2006: Parasitological, hematological and ultrastructural study of the effect of COX-2 inhibitor, pyocyanini pigment and praziquantel on Schistosoma mansoni infected mice. J. Egypt. Soc. Parasitol. 36: 197-220.

Neves, JK, de Lima-Mdo, C, Pereira, VR, de Melo, CM, Peixoto, CA, et al, 2011: Antischistoso- mal action of thioxo-imidazolidine compounds: an ultrastructural and cytotoxicity study. Exp. Parasitol. 128, 1:82-90.

Otubanjo, OA, 1981: Schistosoma mansoni: Astiban-induced damage to tegument and the male reproductive system. Exp. Parasitol. 52: 161-70.

Pax, R, Bennett, JL, Fetterer R, 1978: A benzodiazepine derivative and praziquantel: effects on musculature of Schistosoma mansoni and Schistosoma japonicum. Naunyn Schmied. Arch. Pharmacol. 304, 3:309-15.

Pearce, EJ, Sher, A, 1987: Mechanisms of immune evasion in schistosomiasis. Contrib. Microbiol. Immunol. 8: 219-32.

Popiel, I, Erasmus, DA, 1984: Schistosoma mansoni: ultrastructure of adults from mice treated with oxamniquine. Exp. Parasitol. 58:25462.

Silva, AL, Oliveira, SA, Oliveira, JF, Santiago, EF, Almeida Junior, ASA, et al, 2014: Tegumental changes in adult Schistosoma mansoni induced by a new imidazolidinic derivative. Brit. J. Pharm. Res. 4, 16:1988-2005.

WHO, 1993: Report of a WHO Expert Committee, Technical Report Series, No. 830, Geneva.

WHO, 2017: Schistosomiasis, Fact sheet No 115. URL: http://www.who.int/mediacentre/fact sheets/ fs115/en/.

Xiao, SH, Binqqui, SH, Utzinger, J, Chollet, J, Tanner, M, 2002: Ultrastructural alterations in adult Schistosoma mansoni caused by artemether. Mem. Inst. Oswald. Cruz. Rio de Janeiro, 97, 5:717-24.

Xiao, SH, Catto, BA, 1989: In vitro and in vivo studies of the effect of artemether on Schistosoma mansoni. Antimicrob Agents Chemother. 33:1557-62.

Xiao, SH, Chollet, J, Weiss, NA, Bergquist, R N, Tanner, M, 2000a: Preventive effect of artemether in experimental animals infected with Schistosoma mansoni. Parasitol. Int. 49:19-24.

Xiao, SH, Utzinger, J, Chollet, J, Endriss, Y, N'Goran, EK, et al, 2000b: Effect of artemether against Schistosoma haematobium in exper- 
imentally infected hamsters. Int. J. Parasitol. 30: $1001-6$.

Xiao, SH, Xue, J, Shen, B, 2010: Transmission electron microscopic observation on ultrastructural alterations in Schistosoma japonicum caused by mefloquine. Parasitol. Res. 106:1179-87. Xiao, SH, You, JQ, Yang, YQ, Wang, CZ,

\section{Legend of figures}

Fig. 1: A special device used to determine change in worm length (\% shortening).

Fig. 2: Utramicrograph of control adult $S$. mansoni showing large tubercles (T) with numerous spines (S).

Fig. 3: Utramicrograph of worms tested with $20 \mu \mathrm{g} / \mathrm{ml}$ ART showing loss of spines of few tubercles (arrows).

Fig. 4: Utramicrograph of worms tested with $40 \mu \mathrm{g} / \mathrm{ml}$ ART showing oedematous tegument with formation of vesicles (V) and more loss of spines (arrows).

Fig. 5: Utramicrograph of worms tested with $80 \mu \mathrm{g} / \mathrm{ml}$ ART showing tegumental alterations of S. mansoni with cracks (C) and partial loss of spines (arrows).

Fig. 6: Utramicrograph of worms tested with $100 \mu \mathrm{g} / \mathrm{ml}$ ART showing the distortion with cracks (C), peeling (P), bleb formation (B), loss of spines (arrows) and absence of itertubercular ridges.

Fig. 7: In vitro ART effect in different concentrations on muscle tension of adult $S$. mansoni worms (\% shortening).

Fig. 8: Recording of in vitro effect of ascending ART doses on muscle tension (\% shortening) of S. mansoni adults.
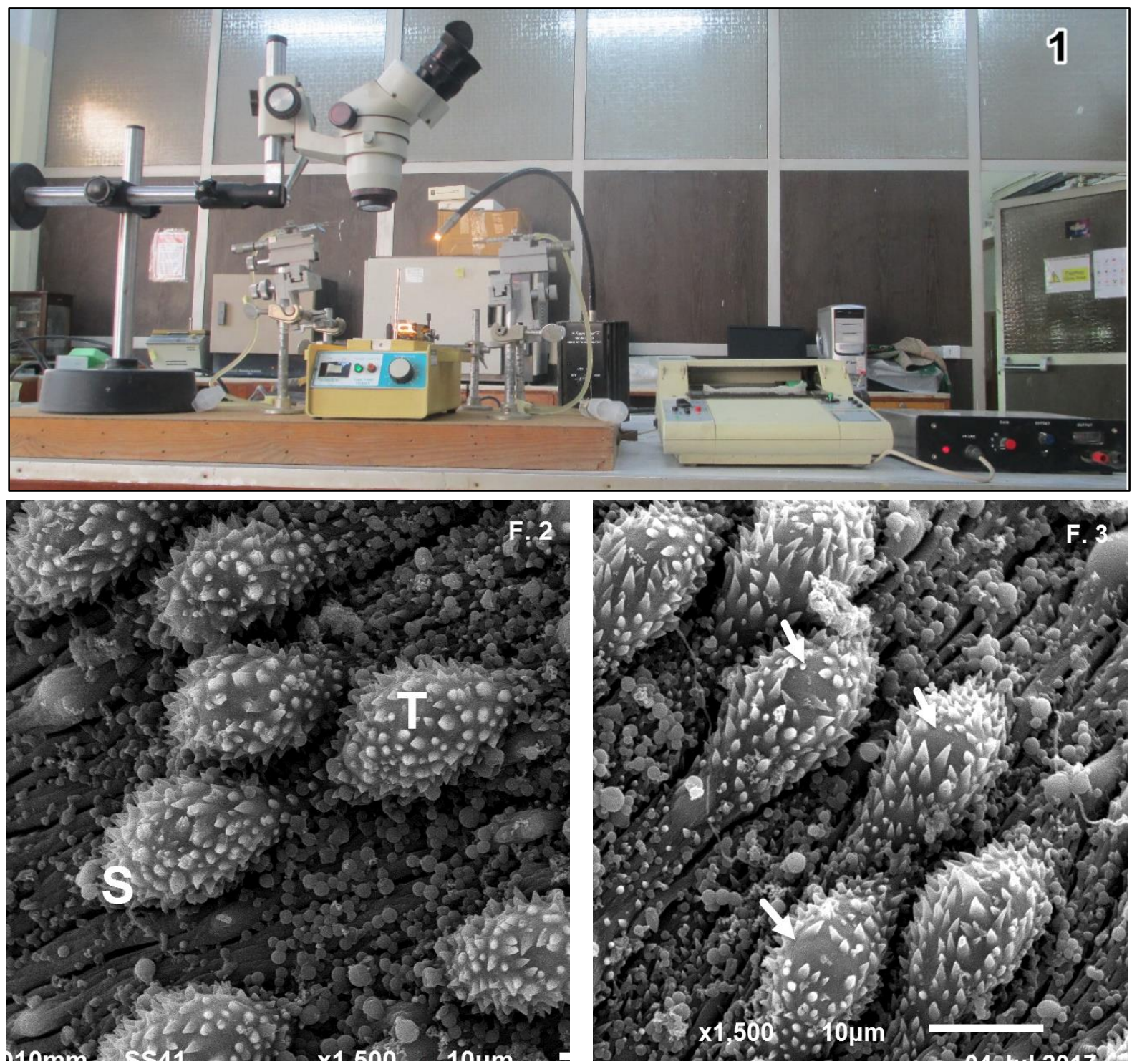

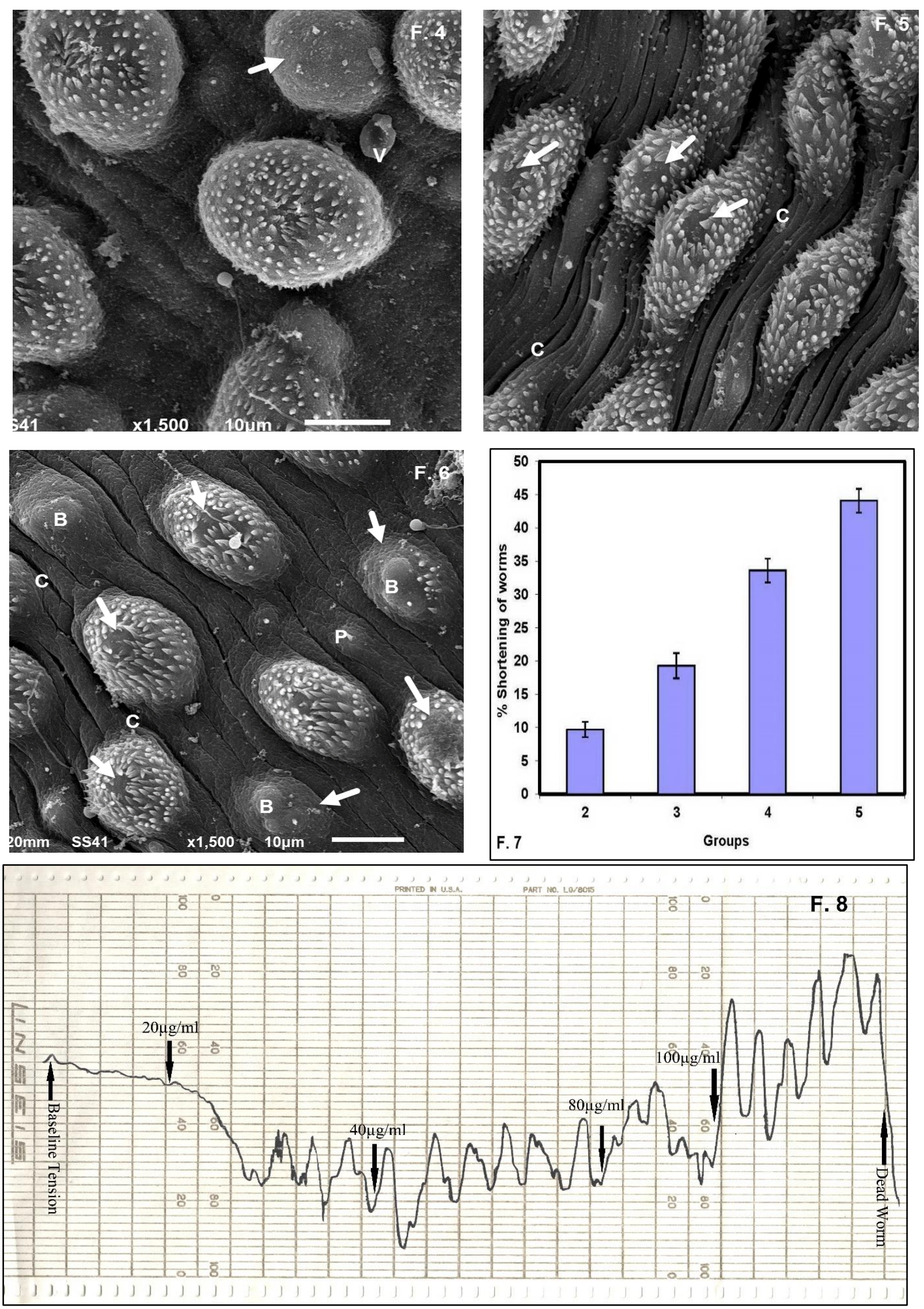